\title{
MICRO SHEAR BOND STRENGTH EVALUATION FOR IMMEDIATELY SEALED DENTINE WITH HYBRID CERAMICS AFTER DIFFERENT PROVISIONALIZATION PERIODS: IN VITRO STUDY
}

\author{
Maha Taymour* and Reham Elbasty*
}

\begin{abstract}
Statement of the problem: CAD/CAM restorations can be immediately cemented after tooth preparation, however, a delay between final impression and restoration delivery is sometimes unavoidable, thus provisionalization period becomes necessary. There are concerns whether this delay would affect the dentin bond strength when bonding to immediately sealed dentin.

Purpose: to study the effect of different provisionalization periods ( 1 and 3 weeks) on the bond strength of immediately sealed dentin to two types of hybrid ceramics

Materials and Methods: A total of sixty ceramic discs were fabricated in this study from CAD/ CAM blocks. The discs were divided into two groups; Group 1: Thirty discs were constructed from polymer-infiltrated-ceramic-network material (VITA ENAMIC) and Group 2: Thirty discs constructed from resin nanoceramic (CERASMART). Each of the previous groups were further subdivided into three equal subgroups according to the provisionalization period as follows; Subgroup 1: Ten discs were cemented to immediately sealed dentin without any provisionalization period, Subgroup 2: Ten discs were cemented to immediately sealed dentin after 1 week of provisionalization and Subgroup 3: Ten discs were cemented to immediately sealed dentin after 3 weeks of provisionalization. Teeth were trimmed to have a flat, midcoronal dentin surfaces. This was followed by immediate dentin sealing of the exposed dentin. Ceramic samples were then obtained by slicing the CAD/CAM blocks with standardized dimensions. For subgroup 1, adhesive cementation was immediately done for the ceramic samples to immediately sealed dentin. For subgroup 2 and 3, the sealed surfaces were coated with a layer of petroleum gel followed by application of a provisional restoration for 1 and 3 weeks respectively. The samples were then immersed in saline solution until the end of the provisionalization period. At the end of these various periods, the provisional restoration was removed and the sealed dentin was cleaned by pumice and water followed by roughening with a coarse diamond stone. This was followed by adhesive cementation of the discs. Micro shear bond strength test was then performed to debond the specimens in a universal testing machine (Lloyd Instruments Ltd, Hampshire, UK) with a crosshead speed of $0.5 \mathrm{~mm} / \mathrm{s}$. The maximum load at failure was recorded in Newtons $(\mathrm{N})$ unit and was divided over the bonded area $\left(\mathrm{mm}^{2}\right)$ to convert to MPa unit. Data was then collected, tabulated and statistically analyzed.
\end{abstract}

\footnotetext{
* Lecturer Fixed Prosthodontic Department, Faculty of Oral and Dental Medicine. Cairo University.
} 
Results: For CERASMART group: It was found that the highest shear bond strength mean \pm SD values were recorded with no provisionalization subgroup $(9.37 \pm 0.35 \mathrm{MPa})$ followed by 1 week provisionalization subgroup $(8.4 \pm 0.12 \mathrm{MPa})$ while the lowest shear bond strength mean \pm SD values were after 3 weeks provisionalization subgroup $(4.48 \pm 0.23 \mathrm{MPa})$. The difference between provisionalization subgroups was statistically significant $(\mathrm{p}=<.0001<0.05)$ as indicated by one way ANOVA test. Pair-wise Tukey's post-hoc tests showed no significant difference ( $\mathrm{p}>0.05$ ) between (no- provisionalization and 1 week provisionalization) subgroups. For VITA ENAMIC group: It was found that the highest shear bond strength mean $\pm \mathrm{SD}$ values were recorded with 3 weeks provisionalization subgroup $(7.3 \pm 0.67 \mathrm{MPa})$ followed by no provisionalization subgroup $(7.08 \pm 1 \mathrm{MPa})$ while the lowest shear bond strength mean $\pm \mathrm{SD}$ values were after 1 week provisionalization subgroup $(5.59 \pm 0.71 \mathrm{MPa})$. The difference between all subgroups was statistically non-significant $(\mathrm{p}=0.2192>0.05)$ as indicated by one way ANOVA test. Effect of ceramic: With no provisionalization; it was found that CERASMART group recorded statistically non-significant higher shear bond strength mean value $(9.37 \pm 0.35 \mathrm{MPa})$ than VITA ENAMIC group $(7.08 \pm 1 \mathrm{MPa})$ as indicated by $\mathrm{t}$-test $(\mathrm{p}=0.0598>0.05)$. After 1 week provisionalization; it was found that CERASMART group recorded statistically non-significant higher shear bond strength mean value $(8.4 \pm 0.12 \mathrm{MPa})$ than VITA ENAMIC group $(5.59 \pm 0.71 \mathrm{MPa})$ as indicated by t-test $(\mathrm{p}=.0540>0.05)$. After 3 weeks provisionalization it was found that VITA ENAMIC group recorded statistically significant higher shear bond strength mean value (7.3 $\pm 0.67 \mathrm{MPa})$ than CERASMART group $(4.48 \pm 0.23 \mathrm{MPa})$ as indicated by t-test $(\mathrm{p}=.0089<0.05)$.

Conclusions: 1) The effect of provisionalization period on microshear bond strength of immediately sealed dentin with indirect restorations is ceramic type dependant. 2) When it is inevitable to cement the final restoration within 3 weeks, VITA ENAMIC ceramic would be a preferred choice compared to CERASMART as it provided higher bond strength when IDS protocol is used. 3) When final restoration cementation is planned immediately or within 1 week of IDS, both ceramics can be used as the difference between them was insignificant.

\section{INTRODUCTION}

Dentin bonding aims to create an interface called the hybrid layer ${ }^{(1,2)}$ by the interpenetration of monomers into the treated dentin surface followed by its polymerization. Some challenges are present during the clinical procedure of dentin-resin hybridization including dentin contamination and susceptibility of the hybrid layer to collapse before being fully polymerized. This led to the idea that dentin should be sealed immediately after tooth preparation as it provides freshly cut dentin substrate which is considered ideal for dentin bonding. ${ }^{(3-5)}$

Immediate dentin sealing prior to impression taking for indirect restorations was first advocated in early $1990 \mathrm{~s}^{(6)}$. When compared to conventional method of dentin sealing that occurred only before final cementation of the restoration, immediate dentine sealing offered multiple advantages as minimizing micro-leakage and hypersensitivity. Besides previous researches showed improved adhesive strength of restorations when dentin was sealed immediately ${ }^{(7-10)}$. Several studies reported higher significant values of bond strength for immediate dentin sealing compared to conventional dentin sealing depending on the test $\operatorname{method}^{(4,11,12)}$. In addition, it was also found that immediate dentine sealing enhanced restoration adaptation ${ }^{(9)}$. In other words, management of the exposed dentin after preparation and during the provisionalization period by immediately sealing it has been shown to play an important role in the overall prognosis of cemented restorations.

Long-term serviceability of adhesive CAD/ CAM restorations still remains a challenging issue 
and relies mainly on the achievement of a strong bond between restoration, the luting cements and the dental tissues ${ }^{(13)}$.

Recently, CAD/CAM hybrid and composite resin blocks with improved properties have invaded the dental market. They are assumed to offer several advantages over the pure ceramic restorations due to their softer characteristics. These advantages include easier machinability and repair of the material ${ }^{(14)}$. A polymer-infiltrated-ceramic-network material (VITA ENAMIC) and nano-hybrid-composite with inorganic nano-ceramic fillers (CERASMART) are two of the most commonly used hybrid ceramics (15,16). VITA ENAMIC contains heterogeneous phases of resin and ceramic with a dual network structure $^{(16,17)}$. Accordingly, it combines the positive properties of ceramics and composites ${ }^{(18)}$ including low rigidity and high fracture toughness ${ }^{(19)}$. As for the CERASMART blocks which contains $71 \%$ silica and barium glass filler by weight in a polymer matrix $^{(19)}$, it is assumed by the manufacturer to have comparable fracture resistance and compressive strength to the commonly used CAD-CAM materials available in the market ${ }^{(16)}$.

Since studies addressing the shear bond strength between hybrid ceramics and immediately sealed denine that has been provisionalized for different periods are still scarce, thus the objective of this study was to study the effect of different provisionalization periods ( 1 and 3 weeks) on the bond strength of immediately sealed dentin to two types of hybrid ceramics

The null hypothesis of the study was that different provisionalization periods will have no effect on immediately sealed dentin bond strength with both types of ceramics

\section{MATERIALS AND METHODS}

A total of sixty ceramic discs were fabricated in this study from CAD/CAM blocks. The discs were divided into two groups; Group 1: Thirty discs constructed from polymer-infiltrated- ceramic-network material (VITA ENAMIC) and Group 2: Thirty discs constructed from resin nanoceramic (CERASMART). Each of the previous groups were further subdivided into three equal subgroups according to the provisionalization period as follows; Subgroup 1: Ten discs were cemented to immediately sealed dentin without any provisionalization period, Subgroup 2: Ten discs were cemented to immediately sealed dentin after 1 week of provisionalization and Subgroup 3: Ten discs were cemented to immediately sealed dentin after 3 weeks of provisionalization

\section{Teeth preparation}

Sixty freshly extracted, sound human upper first molars were selected and used in the study. Teeth were stored in distilled water for no more than 2 weeks. The teeth were centralized and embedded in autopolymerizing acrylic resin in circular copper molds having $2 \mathrm{~cm}$ diameter. Grinding of the occlusal half of the crown was done using a model trimmer (Orthodontic Model Trimmer; Gamberini srl, Bologna, Italy) to create flat, midcoronal dentin surfaces. Ground teeth were then finished with 600grit $\mathrm{SiC}$ paper (Gatorgrit; Ali Industries, Fairborn, Ohio) under water to create a relatively smooth dentin surface with standardized smear layer. The bonding area was demarcated by positioning a piece of adhesive tape with a $5 \mathrm{~mm}$ diameter opening, and it was securely placed on the center of the dentin.

\section{Preparation of the ceramic specimens}

A total of 60 ceramic discs were sectioned from polymer-infiltrated-ceramic-network material (VITA ENAMIC, Vita Zahnfabrik, Bad Sackingen, Germany) and resin nanoceramic (CERASMART, GC Corp., Tokyo, Japan) under water irrigation with a precision cutting machine Isomet 1000 (Buehler, Lake Bluff, USA) into specimens with dimension of $5 \mathrm{~mm}$ diameter and $2 \mathrm{~mm}$ thickness. All sectioned samples were carefully inspected using magnifying lens and examined for any surface defects. Thickness 
of all samples was checked at a point in the middle of each disc and at the margin using a digital caliper.

\section{Immediate dentine sealing and provisionaliza- tion of the samples}

For the three subgroups, the freshly cut teeth were immediately sealed. The demarcated bonded area of dentine in all samples were acid-etched with $32 \%$ phosphoric acid (Scotchbond ${ }^{\mathrm{TM}}$ etching gel, 3M ESPE, USA) for 15 seconds, rinsed with water for 10 seconds then blot dried using a cotton pellet. This was followed by the application of 2 layers of adhesive bond (Single Bond 2, 3M ESPE, USA). The applied adhesive was left to evaporate for 5 seconds and then light polymerized for 10 seconds using light-polymerizing unit (Elipar LED curing unit, 3M ESPE) having curing power of $1200 \mathrm{~mW} /$ $\mathrm{cm}^{2}$. Air -blocking was then done by applying a layer of glycerine gel to limit formation of "oxygen inhibition layer" to the adhesive. This was followed by additional polymerization for 10 seconds.

For subgroup 1, adhesive cementation was immediately done for the ceramic samples. For subgroup 2 and 3 , the sealed surfaces were coated with a layer of petroleum gel and then restored with a provisional restoration material (Protemp $^{\mathrm{TM}} 4,3 \mathrm{M}$ ESPE, USA) which was cemented by an eugenol free provisional cement (Cavex Temporary Cement, Cavex Holland BV) which was left in place for 1 week for subgroup 2 and 3 weeks for subgroup 3 . The samples were then immersed in saline solution at $37^{\circ} \mathrm{C}$ until the end of the provisionalization period. At the end of these various periods, the provisional restoration was removed and the sealed dentin was cleaned by pumice and water followed by roughening with a coarse diamond stone. This was followed by adhesive cementation of the discs.

\section{Adhesive cementation of ceramic restorations}

The bonding surfaces of the ceramic restorations were etched with 5\% hydrofluoric acid (IPS Ceramic Etching gel, Ivoclar Vivadent. Schaan,
Liechtenstein) for 60 seconds, then rinsed under running water for 40 seconds and then dried for 30 seconds with oil free air. A silane-coupling agent (RelyX ${ }^{\mathrm{TM}}$ Cermic Primer. 3M ESPE, USA) was applied and allowed to dry for 1 minute. The dentin bonding agent (Single Bond 2,3M ESPE, USA) was applied to dentin as previously discussed. All discs were adhesively luted with (RelyX ${ }^{\mathrm{TM}}$ Ultimate Clicker $^{\mathrm{TM}}$ Adhesive Resin Cement, 3M ESPE, Germany) dual cured composite resin cement. The base and catalyst were mixed at a 1:1 ratio and applied on the bonding surface of the ceramic discs. Discs were seated and cemented under a constant load of $500 \mathrm{~g}$ for 30 seconds, and excess luting material was removed. The samples were then subjected to light polymerization from the buccal, mesial, lingual, distal and occlusal surfaces for 40 seconds for each surface.

\section{Microshear bond strength test}

Microshear testing was performed to debond the specimens in a universal testing machine (Lloyd Instruments Ltd, Hampshire, UK) with a crosshead speed of $0.5 \mathrm{~mm} / \mathrm{s}$ as shown in figure 1. The maximum load to failure was recorded in Newtons $(\mathrm{N})$ unit and was divided over the bonded area $\left(\mathrm{mm}^{2}\right)$ to convert it to MPa unit. Data was then collected, tabulated and statistically analyzed. Data analysis was performed in several steps. Initially, descriptive statistics for each group results. Two-way analysis of variance ANOVA test of significance was done for comparing variables (material group and provisionalization) affecting mean values. One way ANOVA followed by pair-wise Tukey's post-hoc tests were performed to detect significance between subgroups. Pair-wise student t-test was performed to detect interaction between main groups. Statistical analysis was performed using Aasistat 7.6 statistics software for Windows (Campina Grande, Paraiba state, Brazil). $\mathrm{P}$ values $\leq 0.05$ are considered to be statistically significant in all tests. 


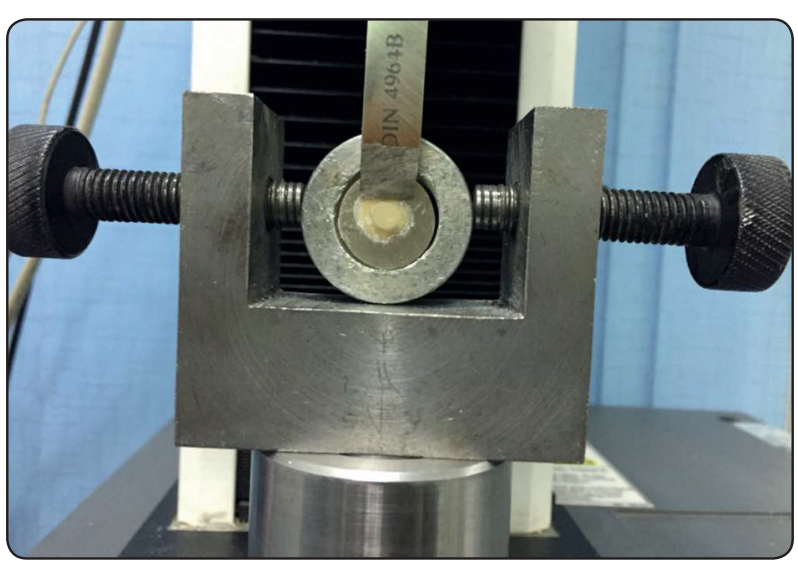

Fig. (1) Bonded dentin - ceramic samples mounted in universal testing machine for microshear bond strength testing.

\section{RESULTS}

Descriptive statistics showing mean values, standard deviations (SD) for microshear bond strength measured in MPa recorded for both ceramic groups as function of provisionalization was summarized in table (1) and graphically represented in figure (2).

\section{For CERASMART group}

It was found that the highest shear bond strength mean $\pm \mathrm{SD}$ values were recorded with

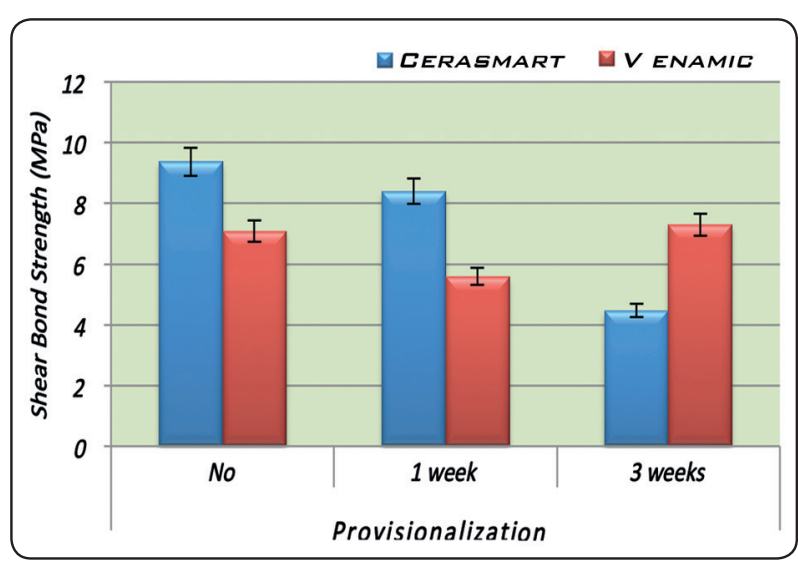

Fig. (2) Column chart showing shear bond strength mean values for both ceramic groups as function of provisionalization

no provisionalization subgroup $(9.37 \pm 0.35 \mathrm{MPa})$ followed by 1 week provisionalization subgroup $(8.4 \pm 0.12 \mathrm{MPa})$ while the lowest shear bond strength mean $\pm \mathrm{SD}$ values were after 3 weeks provisionalization subgroup $(4.48 \pm 0.23 \mathrm{MPa})$. The difference between provisionalization subgroups was statistically significant $(\mathrm{p}=<.0001<0.05)$ as indicated by one way ANOVA test. Pair-wise Tukey's post-hoc tests showed no significant difference $(\mathrm{p}>0.05)$ between (no- provisionalization and 1 week temporization) subgroups.

TABLE (1) Microshear bond strength results (Mean values \pm SD in MPa) for both ceramic groups as function of provisionalization

\begin{tabular}{|c|c|c|c|c|c|c|c|c|}
\hline \multirow{3}{*}{\multicolumn{2}{|c|}{ Variables }} & \multicolumn{3}{|c|}{ CERASMART } & \multicolumn{3}{|c|}{ VITA ENAMIC } & t-test \\
\hline & & \multirow{3}{*}{$\begin{array}{l}\text { Mean } \pm \text { SD } \\
9.37^{\mathrm{A} \pm 0.35}\end{array}$} & \multicolumn{2}{|c|}{$95 \% \mathrm{CI}$} & \multirow{2}{*}{ Mean \pm SD } & \multicolumn{2}{|c|}{$95 \% \mathrm{CI}$} & \multirow{2}{*}{$P$ value } \\
\hline & & & Low & High & & Low & High & \\
\hline \multirow{3}{*}{ Provisionalization } & No & & 8.85 & 9.57 & $7.08^{\mathrm{A}} \pm 1$ & 6.03 & 8.13 & $0.0598 \mathrm{~ns}$ \\
\hline & 1 week & $8.4^{\mathrm{A}} \pm 0.12$ & 8.27 & 8.53 & $5.59^{\mathrm{A}} \pm 0.71$ & 4.85 & 6.34 & $.0540 \mathrm{~ns}$ \\
\hline & 3 weeks & $4.48^{\mathrm{B}} \pm 0.23$ & 4.18 & 4.77 & $7.3^{\mathrm{A}} \pm 0.67$ & 6.59 & 7.30 & $.0089^{*}$ \\
\hline ANOVA & $\mathrm{P}$ value & \multicolumn{3}{|c|}{$<.0001^{*}$} & \multicolumn{3}{|c|}{$0.2192 \mathrm{~ns}$} & \\
\hline
\end{tabular}

Different letter in the same column indicating statistically significant difference $(p<0.05) . *$; significant $(p>0.05) n s ; n o n$ significant $(p>0.05)$ 


\section{For VITA ENAMIC group}

It was found that the highest shear bond strength mean \pm SD values were recorded with 3 weeks provisionalization subgroup $(7.3 \pm 0.67 \mathrm{MPa})$ followed by no provisionalization subgroup $(7.08 \pm 1 \mathrm{MPa})$ while the lowest shear bond strength mean \pm SD values were after 1 week provisionalization subgroup $(5.59 \pm 0.71 \mathrm{MPa})$. The difference between all subgroups was statistically non-significant $(\mathrm{p}=0.2192>0.05)$ as indicated by one way ANOVA test.

\section{Effect of ceramic}

With no provisionalization; it was found that CERASMART group recorded statistically nonsignificant higher shear bond strength mean value $(9.37 \pm 0.35 \mathrm{MPa})$ than VITA ENAMIC group $(7.08 \pm 1 \mathrm{MPa})$ as indicated by t-test $(\mathrm{p}=0.0598>0.05)$.

After 1 week provisionalization; it was found that CERASMART group recorded statistically non-significant higher shear bond strength mean value $(8.4 \pm 0.12 \mathrm{MPa})$ than VITA ENAMIC group $(5.59 \pm 0.71 \mathrm{MPa})$ as indicated by t-test $(\mathrm{p}=.0540$ $>0.05)$.

After 3 weeks provisionalization it was found that VITA ENAMIC group recorded statistically significant higher shear bond strength mean value $(7.3 \pm 0.67$ $\mathrm{MPa})$ than CERASMART group $(4.48 \pm 0.23 \mathrm{MPa})$ as indicated by $\mathrm{t}$-test $(\mathrm{p}=.0089<0.05)$

\section{DISCUSSION}

Adhesive layer debonding from dentin surface seems to be the commonest type of failures in bonded restorations as it represents the weakest link in the tooth restoration complex ${ }^{(8,20-24)}$. Accordingly, many attempts were done to minimize this type of failure. This led to increased application of immediate dentine sealing concept instead of conventional method of delayed dentine sealing in order to minimize postoperative sensitivity and debonding of adhesive restorations
Patients undergoing complex restorative procedures often require variable delays until the restoration is delivered by the laboratory depending on the case complexity. Up till now, data available regarding the bond strength between immediately sealed dentin and recent types of hybrid ceramics after different provisionalization periods is missing. Thus, the aim of this study was to evaluate the reliability of IDS in situations of delayed restoration placement of up to 3 weeks and its effect on the dentin bond strength with two commonly used ceramics using the microshear test.

In spite of in vitro tests variability used to evaluate the dentine ceramic bond strength including shear, tensile, and three point bending, yet, the microshear bond strength test is commonly used than others, due to its easy methodology. ${ }^{(25)}$ As well, it is considered a method where the standard deviation of the results for different bonded substrates are minimum and stable. ${ }^{(26)}$

This study followed the immediate dentin sealing protocol as mentioned by Magne ${ }^{(3)}$

As previously concluded in several studies, 3-step etch \& rinse adhesives have better performance regarding bond strength, aging, and stability of the bonded interface when compared to simplified 1-step dentin adhesives ${ }^{(27-29)}$. This made them more suitable for IDS protocol due to their capability of forming a more hydrophobic resin coating. As a consequence, a 3 step etch and rinse approach was used in our study. A success factor in IDS is the achievement of a reliable resin-to resin bond between the existing resin coating and the subsequently applied resin coating .

To prevent the formation of the oxygen-inhibited layer, a layer of glycerin gel was applied over dentin bonding agent followed by repolymerization of bonding agent for 10 seconds. This step is recommended to maintain the DBA thickness and avoid potential exposure of dentin at later stages during cleaning of the adhesive interface. ${ }^{(30)}$ Besides, the unpolymerized tacky oxygen-inhibited 
layer might interact with the impression material, thus it is better to prevent its formation.

Isolation of the sealed dentin with a layer petroleum jelly was done before direct application of the provisional restoration as suggested by Magne $^{(3)}$. This step was necessary to prevent bonding of provisional materials to sealed dentin, otherwise the removal of provisional restoration later on might result in damage of the immediately sealed layer.

Different methods have been suggested for cleaning tooth surface following removal of provisional restoration including soft-air abrasion (31), air borne particle abrasion with aluminium oxide ${ }^{(9,32-34)}$ and fluoride-free pumice paste systems ${ }^{(3,11,35)}$. In our study, the surface of the dentine was conditioned with pumice and water following removal of the provisional restoration. This method was thought to be less aggressive compared to other methods in the conditioning procedure since this step might be critical as it can lead to possible re-exposure of dentin. However, Stavridakis et al concluded that the possibility of reexposure of dentin due to conditioning methods may not be critical when a filled DBA was used ${ }^{(30)}$. Thus a filled DBA (Single bond 2) was selected for this research

Immediately before the final cementation of the ceramic discs, roughening of the existing adhesive resin using a coarse diamond bur at low speed was done as recommended by Magne (3) in order to enhance the bond with subsequently applied resin. This was followed by coating the previously sealed dentin with bonding agent. Polymerization of bonding agent solely is not indicated at this stage as it would prevent the complete seating of the restoration. Instead it is co-polymerized simultaneously with the subsequently applied resin cement

According to the results of the present study, the null hypothesis stating that different provisionalization periods will have no effect on immediately sealed dentin bond strength was accepted for the VITA ENAMIC group, however it had to be rejected for the CERASMART group where the third subgroup showed lower statistical significant difference compared to other subgroups.

Regarding the results of CERASMART group that showed lower significant bond of the third subgroup compared to other subgroups, can be explained by water penetration phenomena to the sealed dentine during the water storage period preceding final cementation. Although this phenomena also occurred in the VITA ENAMIC group but it caused significant lower bond strength in the CERASMART group. This might be caused by the fact the inorganic filler particles in CERASMART are enclosed in a polymer matrix without interconnections ${ }^{(36)}$. In contrary to the VITA ENAMIC that has ceramic connected network framework $^{(37)}$. This difference in microstructure can justify the unlikness in bond strength after 3 weeks of provisionalization and water storage. However further investigations are needed to support this assumption.

The results of VITA ENAMIC group that showed no significant difference in micro shear bond strength between the three subgroups were consistent with Magne et al ${ }^{(9)}$ who concluded that acceptable bond strength can be maintained between the final restoration and the sealed dentinal surface even up to an extended provisionalization period of 12 weeks. He explained his results according to previous study by Burtscher ${ }^{(38)}$ who postulated similar conclusion. Thus it can be assumed that the combination of IDS procedure with indirectly bonded VITA ENAMIC restorations can benifit from postponing occlusal overloading up to 3 weeks.

For subgroup 1 and 2, CERASMART group recorded statistically non-significant higher bond strength mean values than VITA ENAMIC group - Although the difference was statistically non significant but it can be due to the higher organic matrix of the CERASMART that promotes higher degree of bonding with the resin cement due to the chemical similarity. This was in disagreement with previous study conducted by Nagas et al (39) who revealed higher bond strengths of VITA ENAMIC 
compared to CERASMART. This inconsistency in results might be due to difference in dentin sealing protocols, methodology or storage period.

For subgroup 3, VITA ENAMIC group recorded statistically significant higher shear bond strength mean value than CERASMART group. Again this might be attributed to the higher interpenetrating filler network of the VITA ENAMIC matrix ${ }^{(37)}$.

Although In vitro studies outline relative information when evaluating novel protocols to enhance bonding to dental structures, yet, they still have their limitations and do not substitute clinical studies. The results of the present research revealed the need for further investigations, especially those measuring the effect of thermocycling and fatigue loading on shear bond strength as well as long term clinical prognosis of IDS

\section{CONCLUSIONS}

The following conclusions were obtained:

1. The effect of provisionalization period on microshear bond strength of immediately sealed dentin with indirect restoration is ceramic type dependant

2. When it is inevitable to cement the final restoration within 3 weeks, VITA ENAMIC ceramic would be a preferred choice compared to CERASMART as it provided higher bond strength when IDS protocol is used.

3. When final restoration cementation is planned immediately or within 1 week of IDS, both ceramics can be used as the difference between them was insignificant

\section{REFERENCES}

1. Magne $\mathbf{P}$ and Belser U. Understanding the intact tooth and the biomimetic principle. Chicago: Quintessence Publishing 2002; 270-3.

2. Magne P and Douglas WH. Rationalization of esthetic restorative dentistry based on biomimetics. J Esthet Dent 1999; 11:5-15.
3. Magne P. Immediate dentin sealing: a fundamental procedure for indirect bonded restorations. J Esthet Restor Dent 2005;17:144-54.

4. Paul SJ and Scharer P. The dual bonding technique: a modified method to improve adhesive luting procedures. Int J Periodontics Restor Dent 1997;17:536-45.

5. Paul SJ and Schaerer P. Effect of provisional cements on the bond strength of various adhesive bonding systems on dentine. J Oral Rehabil 1997;24:8-14.

6. Pashley E, Comer R, Simpson M, Horner J, Pashley D and Caughman W. Dentin permeability: sealing the dentin in crown preparations. Oper Dent 1992;17:13-20.

7. Bertschinger C, Paul SJ, Luthy $\mathrm{H}$ and Scharer P. Dual application of dentin bonding agents: effect on bond strength. Am J Dent 1996;9:115-9

8. Magne P and Douglas WH. Porcelain veneers: dentin bonding optimization and biomimetic recovery of the crown. Int J Prosthodont 1999;12:111-21.

9. Magne P, So WS and Cascione D. Immediate dentin sealing supports delayed restoration placement. J Prosthet Dent 2007; 98:166-74

10. Lee $\mathrm{J}$ and Park $\mathrm{S}$. The effect of three variables on shear bond strength when luting a resin inlay to dentin. Oper Dent 2009;34:288-92.

11. Duarte S, de Freitas C, Saad J and Sadan A. The effect of immediate dentin sealing on the marginal adaptation and bond strengths of total-etch and self-etch adhesives. J Prosthet Dent 2009;102:1-9

12. Dietschi D, Monasevic M, Krejci I and Davidson C. Marginal and internal adaptation of class II restorations after immediate or delayed composite placement. J Dent 2002;30:259-69.

13. Bavbek AB, Goktas B, Cekic-Nagas I, Egilmez F, Ergun G and Eskitascioglu G. Micro-shear bond strength of resin cement to dentin after application of desensitizing toothpastes. Acta Odontol Scand 2013;71:952-6.

14. Lauvahutanon S, Takahashi H, Shiozawa M, Iwasaki $\mathrm{N}$, Asakawa Y and Oki M. Mechanical properties of composite resin blocks for CAD/CAM. Dent Mater J 2014; 33:705-10

15. Della Bona A, Corazza P and Zhang Y. Characterization of a polymer-infiltrated ceramic-network material. Dent Mater 2014;30:564-9. 
16. Acar O, Yilmaz B, Altintas SH, Chandrasekaran I and Johnston WM. Color stainability of CAD/CAM and nanocomposite resin materials. J Prosthet Dent 2016;115:71-5.

17. Leung B, Tsoi J, Matinlinna J and Pow E. Comparison of mechanical properties of three machinable ceramics with an experimental fluorophlogopite glass ceramic. J Prosthet Dent 2015;114:440-6.

18. Elsaka SE. Influence of surface treatments on bond strength of metal and ceramic brackets to a novel CAD/CAM hybrid ceramic material. Odontology 2016;104:68-76.

19. Elsaka SE. Bond strength of novel CAD/CAM restorative materials to self-adhesive resin cement: the effect of surface treatments. J Adhes Dent 2014;16:531-40

20. Peumans M, De Munck J, Fieuws S, Lambrechts P, Vanherle $\mathrm{G}$ and Van Meerbeek B. A prospective ten-year clinical trial of porcelain veneers. J Adhes Dent 2004;6:65-76.

21. Beier U, Kapferer I, Burtscher D and Dumfahrt H. Clinical performance of porcelain laminate veneers for up to 20years. Int J Prosthodont 2012;25:79-85.

22. Van Meerbeek B, Peumans M, Gladys S, Braem M, Lambrechts $\mathrm{P}$ and Vanherle G. Three-year clinical effectiveness of four total-etch dentinal adhesive systems in cervical lesions. Quintessence Int 1996;27:775-84

23. Van Meerbeek B, Perdigao J, Lambrechts P and Vanherle G. The clinical performance of adhesives. J Dent 1998; 26:1-20.

24. De Munck J, Van Landuyt K, Peumans M, Poitevin A, Lambrechts P, Braem M and Van Meerbeek B. A critical review of the durability of adhesion to tooth tissue: methods and results. J Dent Res 2005;84:118-32.

25. Haselton D, Diaz-Arnold A and Dunne J: Shear bond strengths of 2 intraoral porcelain repair systems to porcelain or metal substrates. J Prosthet Dent 2001;86:526-531

26. Hatta M, Shinya A, Yokoyama D, Gomi H, Vallittu P and Shinya A: The effect of surface treatment on bond strength of layering porcelain and hybrid composite bonded to zirconium dioxide ceramics. J of Prosthod Res 2011; 55: 146-153.

27. Van Meerbeek B, De Munck J, Yoshida Y, Inoue S, Vargas $\mathrm{M}$ and Vijay P. Adhesion to enamel and dentin: current status and future challenges. Oper Dent 2003;28:215-35.
28. De Munck J, Van Meerbeek B, Satoshi I, Vargas M, Yoshida Y and Armstrong S. Microtensile bond strengths of one- and twostep self-etch adhesives to bur-cut enamel and dentin. Am J Dent 2003;16:414-20.

29. Breschi L, Mazzoni A, Ruggeri A, Cadenaro M, Di Lenarda $\mathrm{R}$ and De Stefano Dorigo E. Dental adhesion review: Aging and stability of the bonded interface. Dent Mater ; 2007 Apr 16

30. Stavridakis MM, Krejci I and Magne P. Immediate dentin sealing of onlay preparations: thickness of pre-cured Dentin Bonding Agent and effect of surface cleaning. Oper Dent 2005;30:747-57.

31. Rocca GT, Gregor L, Sandoval MJ, Krejci I and Dietchi D. In vitro evaluation of marginal and internal adaptation after occlusal stressing of indirect class II composite restorations with different resinous bases and interface treatments. Post-fatigue adaptation of indirect composite restorations. Clin Oral Investig 2012;5:1385-93.

32. Magne P, Kim TH, Cascione D and Donovan TE. Immediate dentin sealing improves bond strength of indirect restorations. J Prosthet Dent 2005;94:511-9.

33. Magne P, Paranhos MP, Hehn J, Oderich E and Boff LL. Selective masking for thin indirect restorations: can the use of opaque resin affect the dentin bond strength of immediately sealed preparations. J Dent 2011;39:707-9.

34. Dillenburg AL, Soares CG, Paranhos MP, Spohr AM, Loguercio $\mathrm{AD}$ and Burnett Jr LH. Microtensile bond strength of pre-hybridized dentin: storage time and surface treatment effects. J Adhes Dent 2009;11:231-7.

35. Dagostin A and Ferrari M. Effect of resins sealing of dentin on the bond strength of ceramic restorations. Dent Mater 2002;18:304-10.

36. Coldea A, Swain MV and Thiel N. Mechanical properties of polymer-infiltrated-ceramic-network materials. Dent Mater 2013;29:419-26.

37. Vita. VITA ENAMIC (B) Technical and scientific documentation. 2013.

38. Burtscher P. Stability of radicals in cured composite materials. Dent Mater 1993;4:218-21.

39. Nagas I, Ergun G, Egilmez F, Vallittu P and Lassila L: Micro-shear bond strength of different resin cements to ceramic/glass-polymer CAD-CAM block materials. J of Prosthod Res 2016;20: 265-273. 